\title{
The Prevalence of Rapid Eye Movement Sleep Behavior Disorder in Amyloid Positron Emission Tomography Positive Alzheimer's Disease
}

\author{
Hyun-Suk Kim, Hyun Joon Lee, Dong-Jin Shin, Yeong-Bae Lee, Young Noh, Kee Hyung Park \\ Department of Neurology, College of Medicine, Gachon University, Gil Medical Center, Incheon, Korea
}

아밀로이드 영상 양성인 알츠하이머병에서의 렘수면행동장애 유병률 연구

김현석, 이현준, 신동진, 이영배, 노 영, 박기형

가천대학교 의과대학 신경과학교실

Received November 25, 2019

Revised December 23, 2019

Accepted December 26, 2019

Address for correspondence

Kee Hyung Park, MD, PhD

Department of Neurology,

College of Medicine

Gachon University,

Gil Medical Center,

21 Namdong-daero 774beon-gil

Namdong-gu,

Incheon 21565, Korea

Tel: +82-32-460-3346

Fax: +82-32-460-3344

E-mail: khpark@gachon.ac.kr
Objectives: Rapid eye movement (REM) sleep behavior disorder (RBD) is well known as a prodromal symptom of neurodegenerative disease, especially $\alpha$-synucleinopathy. In the previous literature, it has been reported the incidence rate of RBD in Alzheimer's disease (AD) is about 10\%. This incidence rate is relatively low, if we consider that nearly half of AD patients also have Lewy body pathology. The objective of this study is to determine the incidence rate of RBD among patients with $\mathrm{AD}$, confirmed by amyloid positron emission tomography (PET) image. Methods: We enrolled 57 patients with clinically probable AD patients who identified AD pathology in amyloid PET scan. RBD was evaluated with REM sleep behavior disorder questionnaire-Korean vesion (RBDQ-KR), which validated the RBD screening questionnaire as Korean version to confirm RBD. Detailed neuropsychological tests were measured using the Seoul Neuropsychological Screening Battery (SNSB). Results: We analyzed RBDQ-KR data collected from 57 AD patients. Dementia due to $\mathrm{AD}$ was 36 patients (63.2\%) and mild cognitive impairment (MCI) due to $\mathrm{AD}$ was 21 (36.8\%). AD with RBD was 14 (24.6\%). Among these, $\mathrm{AD}$ dementia with RBD was 13 (36.1\%), and MCI due to $\mathrm{AD}$ with $\mathrm{RBD}$ was 1 (4.8\%). There were no significant differences in cognitive function between the patients with or without RBD, evaluated by detailed neuropsychological test. Conclusions: In this study, the incidence of $\mathrm{RBD}$ in $\mathrm{AD}$ was not rare; therefore, if the patient shows symptoms of RBD, we should not rule out $\mathrm{AD}$

J Sleep Med 2019;16(2):102-108

\section{서 론}

렘수면행동장애[rapid eye movement(REM) sleep behavior disorder, RBD]는 1986년 Schenck 등이 처음 명명한 임 상군으로 렘수면(REM sleep) 동안 꿈 내용을 행동으로 하고 과격한 행동을 보이는 것을 특징으로 한다. ${ }^{1}$ 정상적인 렘수 면 동안 안구 운동을 제외한 근육 마비가 생기지만 RBD 환 자는 이러한 근육 활동 억제가 적절히 이루어지지 않는다. 따

This is an Open Access article distributed under the terms of the Creative Commons Attribution Non-Commercial License (https://creativecommons.org/licenses/by-nc/4.0) which permits unrestricted non-commercial use, distribution, and reproduction in any medium, provided the original work is properly cited.
라서 수면질환 분류 진단기준에 따라 환자의 특징적인 병력 과 비디오 수면다원검사를 통하여 환자의 렘수면 동안 이상 행동 및 턱 근전도 활동 증가소견을 확인함으로써 $\mathrm{RBD}$ 를 진단할 수 있다. RBD의 유병률은 정확히 알려져 있지는 않 지만 대략적으로 $0.5 \sim 1 \%$ 정도로 알려져 있으며, 노인에서는 약 $2 \%$ 까지도 보고되고 있다.,3

$\mathrm{RBD}$ 는 그동안 수면장애로 많은 연구가 이루어졌으나 최 근에는 레비체(Lewy body) 병리로 인해서 발생하는 레비체 질환(Lewy body disease)의 전구증상으로써 중요성이 강조 되고 있다. $\mathrm{RBD}$ 는 파킨슨병의 33 50\%, 다계통위축증의 80 $95 \%$, 레비체치매의 $80 \%$ 에서 파킨슨 증상 발생 5 10년 전에 
나타난다고 알려져 있다. ${ }^{4-9}$ 하지만 최근 비정상 아밀로이드 침착을 주된 병리소견으로 하는 알츠하이머병(Alzheimer's disease, $\mathrm{AD}$ ) 환자에서도 약 $10 \%$ 미만에서 $\mathrm{RBD}$ 를 보였다는 보고가 있었다..$^{10-12}$ 이러한 연구결과들은 알츠하이머병에서 가장 중요한 뇌조직의 베타 아밀로이드 침착을 확인하지 않 고 임상적으로 진단한 환자들을 대상으로 한 연구를 통해 밝 혀졌다. 하지만 알츠하이머병에서도, 연구에 따라 약 40 50\% 에서 레비체 병리소견을 공유한다는 최근 연구결과를 고려 할 때 $\mathrm{AD}$ 환자에서 $\mathrm{RBD}$ 의 유병률이 저평가되었을 가능성 이 있다. ${ }^{13-17}$ 이에 본 연구에서는 아밀로이드 positron emission tomography(PET) 영상을 통해 뇌조직의 베타아밀로이 드 병리의 침착소견을 확인한 알츠하이머병 환자를 대상으 로 RBD가 얼마나 나타나는지 확인하고자 했다.

\section{방 법}

\section{대 상}

본 연구는 전향적 단면연구로 2019년 1월부터 2019년 4월 까지 길병원 뇌건강센터 외래에 인지기능 저하를 주소로 내 원한 환자들 중 아밀로이드 양전자단층촬영 (amyloid PET$\mathrm{CT}$ )에서 양성소견을 보인 65 명의 알츠하이머병 환자들 중, 신경심리검사 결과가 불충분한 환자 8 명을 제외한 57 명의 알 츠하이머병 환자를 대상으로 하였다. 알츠하이머병은 미국 국립노화연구소 및 알츠하이머협회(National Institute on Aging and the Alzheimer's Association, NIA-AA)의 기준에 따라 진단된 dementia due to $\mathrm{AD}$ 와 mild cognitive impairment due to $\mathrm{AD}$ 환자를 모두 포함하였다. ${ }^{18,19}$ 양전자단층촬 영에는 flutemetamol, florobetaben, florbetapir를 사용하였 고, 뇌 구조 영상은 Simens 3T MRI를 이용했다.

\section{연구의 진행}

연구 참여에 동의한 알츠하이머병 환자들에게 한국판 RBD 선별검사(REM sleep behavior disorder questionnaire-Korean version, RBDQ-KR) 작성에 대하여 교육한 후, 선별 검 사지를 작성하도록 하였다. ${ }^{20}$ 환자가 설문 작성에 어려움을 호소할 경우 함께 생활하는 보호자와 같이 작성하도록 하였 다. 검사 항목은 평상시의 경험 및 최근 1 년간의 증상 발생 빈도에 대하여 조사하였고, 한국판 RBD 선별검사 표준화 연 구 진행 방식과 동일하게 환자가 기억나지 않을 경우 0점으 로 간주하였다.

\section{신경심리검사}

모든 환자들은 한국판 간이정신상태검사, ${ }^{21}$ 치매척도검사, ${ }^{22}$
임상치매평가척도, ${ }^{23}$ 한국판 $\mathrm{RBD}$ 선별검사, ${ }^{24}$ 그리고 일상생 활수행능력검사[Korean instrumental activities of daily living(ADL)]를 포함한 서울신경심리검사(Seoul Neuropsychiatric Screening Battery, SNSB)를 진행하였다. 25,26 신경심 리검사는 $\mathrm{RBD}$ 선별검사에서 최근 1년간의 빈도를 확인하는 점을 고려하여 최근 1 년 이내의 검사 결과를 기준으로 자료 를 수집 및 분석하였다.

$\mathrm{SNSB}$ 는 다양한 인지기능을 종합적으로 평가하여 치매평 가에 사용할 수 있도록 2003년 강연욱 등에 의해 국내에서 개 발한 검사 총집으로, 주의집중력(digit span: forward/backward, letter cancellation), 언어능력 및 그와 관련된 기타 능 력들(spontaneous speech, comprehension, repetition, reading, writing, finger naming, calculation, body part identification, Korean Boston naming test, praxis), 시공간적 지각 및 구성 능력(block design, clock drawing test, Rey complex figure test copy), 기억력(Seoul verbal learning test, Rey complex figure test memory) 및 전두엽 기능[go no go test, fist edge palm test, controlled oral word association test (COWAT), luria loop test, alternating hand movement, color word stroop test]에 대한 표준화된 평가 항목으로 구성되어 있다.

\section{한국판 렘수면행동장애 선별검사(RBDQ-KR)}

알츠하이머병 환자들의 RBD 동반 여부는 RBDQ-KR을 이용하여 조사하였다. 이 설문지는 2010 년 $\mathrm{Li}$ 등에 의해 개발 된 REM sleep behavior disorder questionnaire-Hong Kong (RBDQ-HK)의 한국어판으로, ${ }^{27}$ 꿈과 관련된 5 개의 문항과 수면 기간 보인 이상행동과 관련된 8개의 문항을 합쳐 총 13 개의 질문으로 구성되어 있고, 이에 대하여 환자(또는 수면 파트너가 동반하여)가 설문지에 표시할 수 있도록 이루어져 있다. 설문지는 총 100 점 만점으로 일생 동안의 경험을 묻는 항목(0 20점)과 최근 1년간 얼마나 자주 경험했는지에 대한 빈도를 묻는 항목(0 80점)을 구분하여 설문하고, 이상행동과 관련된 문항에 대해서는 가산점을 부여하여 평가하도록 되 어 있다. RBDQ-HK는 18/19점을 절단점으로 했을 때 민감 도 $82.2 \%$, 특이도 $69.9 \%$ 를 보였고, $\mathrm{RBDQ}-\mathrm{KR}$ 은 18.5 점에 서 민감도 $93.3 \%$, 특이도 $89.5 \%$ 로 최적의 절단점을 보였고, $\mathrm{RBD}$ 에 대한 선별검사로서의 유용성과 타당성을 보였다. ${ }^{20}$

\section{일상생활 수행 능력(ADL scales)}

대소변 가리기, 화장실 사용하기, 목욕하기, 식사하기 등의 기본적 일상생활 능력 평가와 전화 사용, 물건 구입, 재정 관 리, 취미 생활하기 등의 도구적 일상생활 능력 평가를 위하 
여 $\mathrm{Kim}$ 이 신뢰도와 타당도를 분석한 한국어판 바텔 일상활 동 지표(Korean Barthel ADL index) 및 2003년 Kang 등이 신뢰도와 타당도를 검증한 한국어판 도구적 일상활동 지표 (Korean instrumental ADL index) 검사를 진행하였다. ${ }^{25,28}$

\section{통계 처리}

평가 변수에 대한 분석은 환자가 작성한 설문 및 의무기록 데이터베이스를 기반으로 하였다. 설문을 모두 작성하지 않 았거나 신경심리검사를 시행하지 않은 경우 통계 분석에서 제외시켰다. $\mathrm{RBDQ}-\mathrm{KR}$ 에서 $\mathrm{RBD}$ 가 확인된 환자와 확인되 지 않은 환자로 구분하여 알츠하이머병과의 연관성을 분석 하였다. 환자들의 $\mathrm{RBD}$ 의 동반 여부와 이에 따른 인지기능 의 차이를 확인하기 위하여 카이제곱검정을 하였다. 통계적 유의성은 $p<0.05$ 수준으로 산정하였다. 모든 수집된 자료는

Table 1. Demographics of participants

\begin{tabular}{lc}
\hline \multicolumn{1}{c}{ Characteristics } & $(\mathrm{n}=57)$ \\
\hline Age (yr) & $72.8 \pm 8.4$ \\
Sex female (n, \%) & $30(52.6)$ \\
Duration of sx (mon) & $38.6 \pm 20.5$ \\
Education duration (yr) & $8.7 \pm 5.4$ \\
Dementia (n, \%) & $36(63.2)$ \\
AD with RBD (n, \%) & $14(24.6)$ \\
\hline
\end{tabular}

AD: Alzheimer's disease, RBD: rapid eye movement sleep behavior disorder
SPSS 17.0(SPSS Inc., Chicago, IL, USA)을 이용하여 분석 하였다.

\section{결 과}

대상 환자 총 57 명의 임상 양상을 Table 1에 요약하였다. 환자들의 평균 연령은 $72.8 \pm 8.4$ 세였다. 이 중 남자 27 명 (47.4\%)이었고, 여자 30명 (52.6\%)이었다. 환자들은 평균적으 로 $8.7 \pm 5.4$ 년 교육받았고, 인지 저하는 연구 시점으로부터 $38.6 \pm 20.5$ 달 전부터 시작되었다. 알츠하이머병 환자 중 14 명(24.6\%)에서 $\mathrm{RBD}$ 를 보였다.

$\mathrm{RBD}$ 는 알츠하이머병 치매 환자에서 13 명(36.1\%)으로 경 도인지장애의 1 명(4.8\%)에 비하여 유의미하게 많은 비율을 보였다(Table 2). 또한 알츠하이머병 치매와 알츠하이머병에 의한 경도인지장애 환자에서 나이, 한국판 간이정신상태검 사, 치매척도검사, 임상치매평가척도, $\mathrm{RBDQ}-\mathrm{KR}$, 일상생활 수행능력검사에서 유의미한 차이를 보였으나 성별, 교육 정 도, 질병 기간의 항목에서는 유의미한 차이를 보이지 않았다.

나이, 성별, 교육, 유병 기간은 RBD 유무에 따른 양쪽 군에 서 유의미한 차이를 보이지 않았다(Table 3). 신경심리검사에 서 $\mathrm{RBD}$ 를 보인 환자군과 보이지 않은 환자군에서 COWAT -supermarket 항목을 제외한 모든 항목에서 통계적으로 유 의미한 차이는 보이지 않았다. apolipoprotein $\mathrm{E}(\mathrm{APOE}) \varepsilon 4$ 를 적어도 1 개 이상 보인 환자의 비율 역시 양쪽 군에서 유

Table 2. Characteristics of $A D$ dementia and $M C l$ due to $A D$

\begin{tabular}{|c|c|c|c|}
\hline & \multicolumn{3}{|c|}{$\mathrm{AD}$} \\
\hline & Dementia $(\mathrm{n}=36,63.2 \%)$ & $\operatorname{MCI}(n=21,36.8 \%)$ & $p$ \\
\hline Age (yr) & $71.3 \pm 9.4$ & $75.4 \pm 5.4$ & 0.038 \\
\hline Sex female $(n, \%)$ & $20(55.6)$ & $10(47.6)$ & 0.563 \\
\hline Duration of sx (mon) & $40.9 \pm 21.0$ & $34.8 \pm 19.6$ & 0.280 \\
\hline Education duration (yr) & $9.0 \pm 5.6$ & $8.2 \pm 5.1$ & 0.599 \\
\hline With RBD (n, \%) & $13(36.1)$ & $1(4.8)$ & 0.008 \\
\hline RBDQ-KR score & $16.5 \pm 21.0$ & $4.1 \pm 7.3$ & 0.002 \\
\hline K-MMSE & $20.1 \pm 5.2$ & $24.8 \pm 2.9$ & $<0.001$ \\
\hline $\mathrm{CDR}$ & $0.8 \pm 0.5$ & $0.5 \pm 0.2$ & 0.001 \\
\hline SOB & $5.0 \pm 2.9$ & $1.7 \pm 0.9$ & $<0.001$ \\
\hline GDS & $4.0 \pm 0.8$ & $2.9 \pm 0.5$ & $<0.001$ \\
\hline B-IADL & $19.6 \pm 1.0$ & $20.0 \pm 0.0$ & 0.020 \\
\hline K-IADL $(\mathrm{n}=56)$ & $0.9 \pm 0.6(n=35)$ & $0.3 \pm 0.2(\mathrm{n}=21)$ & $<0.001$ \\
\hline At least 1 APOE $\varepsilon 4$ (n, \%) & $21(58.3)$ & $14(66.7)$ & 0.533 \\
\hline
\end{tabular}

AD: Alzheimer's disease, MCI: mild cognitive impairment, REM: rapid eye movement, RBD: REM sleep behavior disorder, RBDQ-KR: REM sleep behavior disorder questionnaire-Korean version, K-MMSE: Korean Mini-Mental State Examination, CDR: clinical dementia rating, SOB: sum of boxes, GDS: global deterioration scale, B-IADL: Barthel instrumental activities of daily living, K-IADL: Korean instrumental activities of daily living, APOE: apolipoprotein E 
Table. 3 Correlation between cognition parameters in $A D$ with RBD and AD without RBD

\begin{tabular}{|c|c|c|c|}
\hline & $\mathrm{AD}$ with $\mathrm{RBD}(\mathrm{n}=14)$ & $\mathrm{AD}$ without $\mathrm{RBD}(\mathrm{n}=43)$ & $p$ \\
\hline Age (yr) & $73.4 \pm 8.7$ & $72.6 \pm 8.4$ & 0.773 \\
\hline Sex female $(n, \%)$ & $4(28.6)$ & $26(60.5)$ & 0.063 \\
\hline Duration of sx (mon) & $42.6 \pm 23.1$ & $37.4 \pm 19.7$ & 0.413 \\
\hline Education duration (yr) & $10.5 \pm 5.1$ & $8.2 \pm 5.4$ & 0.161 \\
\hline At least 1 APOE $\varepsilon 4$ (n, \%) & $8(57.1)$ & $27(62.8)$ & 0.706 \\
\hline K-MMSE & $19.8 \pm 5.7$ & $22.5 \pm 4.7$ & 0.081 \\
\hline $\mathrm{CDR}$ & $0.9 \pm 0.6$ & $0.6 \pm 0.4$ & 0.104 \\
\hline SOB & $5.3 \pm 3.8$ & $3.3 \pm 2.4$ & 0.085 \\
\hline GDS & $3.9 \pm 1.0$ & $3.4 \pm 0.8$ & 0.098 \\
\hline B-IADL & $19.4 \pm 1.3$ & $19.8 \pm 0.6$ & 0.269 \\
\hline K-IADL $(\mathrm{n}=55)$ & $1.0 \pm 0.7(n=13)$ & $0.6 \pm 0.5(n=42)$ & 0.050 \\
\hline RBDQ-KR score & $39.1 \pm 17.3$ & $3.0 \pm 4.4$ & $<0.001$ \\
\hline Digit span-F & $5.1 \pm 2.1$ & $5.2 \pm 1.3$ & 0.792 \\
\hline Digit span-B & $2.8 \pm 1.1$ & $3.0 \pm 1.1$ & 0.616 \\
\hline Repetition & $14.1 \pm 3.2$ & $14.5 \pm 1.6$ & 0.475 \\
\hline K-BNT $(n=52)$ & $34.0 \pm 14.0(\mathrm{n}=12)$ & $39.6 \pm 13.5(n=40)$ & 0.218 \\
\hline Praxis-ideomotor & $4.4 \pm 1.3$ & $4.4 \pm 0.9$ & 0.858 \\
\hline Calculation & $8.9 \pm 3.4$ & $9.7 \pm 2.8$ & 0.431 \\
\hline SVLT-immediate & $11.1 \pm 4.4$ & $13.1 \pm 5.1$ & 0.196 \\
\hline SVLT-delayed & $0.8 \pm 1.6$ & $1.1 \pm 1.8$ & 0.522 \\
\hline SVLT-recognition & $15.6 \pm 2.7$ & $16.0 \pm 3.1$ & 0.681 \\
\hline RCFT-immediate & $4.1 \pm 4.4$ & $5.9 \pm 5.9$ & 0.298 \\
\hline RCFT-delayed & $3.2 \pm 3.9$ & $4.3 \pm 5.8$ & 0.505 \\
\hline RCFT-recognition & $15.4 \pm 2.9$ & $16.1 \pm 2.7$ & 0.392 \\
\hline Contrasting program $(\mathrm{n}=55)$ & $19.0 \pm 1.7(n=14)$ & $18.2 \pm 4.2(n=41)$ & 0.489 \\
\hline Go no go $(n=54)$ & $15.8 \pm 2.9(n=14)$ & $13.8 \pm 6.6(n=40)$ & 0.140 \\
\hline COWAT-animal & $8.9 \pm 4.0$ & $10.6 \pm 4.8$ & 0.252 \\
\hline COWAT-supermarket $(\mathrm{n}=56)$ & $6.4 \pm 3.5(n=13)$ & $10.0 \pm 4.3(n=43)$ & 0.009 \\
\hline COWAT-phonemic $(\mathrm{n}=53)$ & $12.9 \pm 6.9(n=12)$ & $14.4 \pm 8.4(n=41)$ & 0.588 \\
\hline Stroop test-word $(\mathrm{n}=55)$ & $94.7 \pm 30.0(n=12)$ & $99.1 \pm 26.2(n=43)$ & 0.616 \\
\hline Stroop test-color $(\mathrm{n}=55)$ & $57.7 \pm 22.0(\mathrm{n}=12)$ & $55.5 \pm 30.1(n=43)$ & 0.820 \\
\hline
\end{tabular}

Values denote means \pm standard deviations. AD: Alzheimer's disease, REM: rapid eye movement, RBD: REM sleep behavior disorder, APOE: apolipoprotein E, K-MMSE: Korean Mini-Mental State Examination, CDR: clinical dementia rating, SOB: sum of boxes, GDS: global deterioration scale, B-IADL: Barthel instrumental activities of daily living, K-IADL, Korean instrumental activities of daily living, RBDQ-KR: REM sleep behavior disorder questionnaire-Korean version, K-BNT: Korean Version-Boston Naming test, SVLT: Seoul verbal learning test, RCFT: Rey-Osterrieth complex figure test, COWAT: controlled oral word association test

의미한 차이를 보이지 않았다.

\section{고 찰}

본 연구는 아밀로이드 영상검사를 통해 확진한 알츠하이 머병 환자를 대상으로 $\mathrm{RBD}$ 의 빈도를 확인하였다는 점에서 의미가 있다.

이전 연구들은 National Institute of Neurological and
Communicative Disorders and Stroke and Alzheimer's Disease and Related Disorders Association(NINCDS-ADRDA) 진단기준에 따라 임상양상으로 알츠하이머병 치매를 진단하 는 경우가 많았다. 하지만 NINCDS-ADRDA 진단기준을 따 를 경우 유력 알츠하이머병 치매(probable $\mathrm{AD}$ dementia)의 경우 민감도 $81 \%$, 특이도 $70 \%$, 가능 알츠하이머병 치매(possible $\mathrm{AD}$ dementia)의 경우 민감도 $93 \%$, 특이도 $48 \%$ 로 특이 도가 낮다는 문제점이 있었다. ${ }^{29}$ 이에 NIA-AA에서는 표지 
자(biomarkers)를 기반으로 한 새로운 진단기준을 제시하였 으며, ${ }^{30}$ 최근 이를 통한 진단 및 연구가 활발히 이루어지고 있 다. NIA-AA에서 사용한 표지자는 아밀로이드 표지자(amyloid biomarker)와 신경퇴행 표지자(neurodegeneration marker)로 구분할 수 있다. 아밀로이드 표지자는 영상검사와 뇌척수검사를 통해 아밀로이드의 유무로 확인할 수 있다. 그 리고 신경퇴행 표지자는 MRI 영상에서 관찰되는 내측 측두 엽 위축과 F-18 fluorodeoxyglucose-PET에서 관찰되는 특 징적인 대사저하, 그리고 뇌척수검사에서 타우단백의 증가 를 관찰함으로써 평가할 수 있다. ${ }^{21}$ 본 연구에 포함된 모든 환 자들은 뇌 MRI와 아밀로이드 PET 촬영을 하여 뇌조직의 아 밀로이드 침착을 확인하였다. 아밀로이드 양전자단층촬영에 는 fluemetamol, florobetaben florbetapir 세 종류의 리간드 가 사용된다. 뇌 부검연구와 아밀로이드 PET를 비교한 이전 연구에서 이들 검사의 민감도는 각각 $88 \%, 97.9 \%, 92 \%$, 특이 도는 각각 $88 \%, 88.9 \%, 100 \%$ 로 보고된 바 있다. ${ }^{31-33}$ 본 연구 에서는 flutemetamol과 florobetaben을 리간드로 사용한 양 전자단층촬영을 이용하여 아밀로이드 바이오마커를 확인한 환자들을 대상으로 하였다.

$\mathrm{RBD}$ 유무를 평가하기 위해서 본 연구에서는 RBDQ-KR 설문을 이용하였다. 기존에 많이 사용되어 온 the RBD screening questionnaire(RBDSQ)는 10문항(총 13점)으로 이루어 져 있고, 절단점을 5점으로 하였을 때 $96 \%$ 의 민감도와 $56 \%$ 의 특이도로 $\mathrm{RBD}$ 를 간편하게 평가할 수 있는 장점이 있으 나, 예/아니오로 답이 구성되어 있기 때문에 증상의 중증도 와 빈도를 반영하기 힘든 단점이 있었다. ${ }^{34}$ 그리고 한국어 버 전으로 개발된 RBDSQ-Korean version(RBDSQ-K)는 RBD 에 대하여 건강한 대상자에 대해서는 정상인과 폐쇄성 수면 무호흡을 가진 환자의 절단점을 달리 제시하고 있어 수면다 원검사를 시행하지 않은 상황에서 적용하기 어렵다는 제한 점이 있었다. ${ }^{24}$ 또한 16 개의 문항으로 이루어져 있는 Mayo sleep questionnaire(MSQ)는 노인, 치매 환자를 대상으로 $\mathrm{RBD}$ 선별을 위한 타당성 평가에서 민감도 98\%, 타당도 $74 \%$ 를 보였으나, $\mathrm{RBD}$ 와 관련된 질문은 한 문항으로, 세부 문항 을 포함하더라도 5 개에 불가하다는 단점이 있다. ${ }^{35}$ 본 연구에 서 사용한 RBDQ-KR은 RBDSQ와는 달리 설문을 통하여 증상의 빈도와 중등도를 평가할 수 있고, 수면다원검사를 하 지 않고도 $93.3 \%$ 의 민감도와 $89.5 \%$ 의 특이도 $\mathrm{RBD}$ 를 선별할 수 있다는 장점이 있다. ${ }^{20}$

$\mathrm{RBD}$ 는 뇌간의 배외측 피개신경핵(laterodorsal tegmental nucleus), 피개 각교신경핵(pedunculopontine nucleus), 청반 핵(locus coerulues) 등 렘수면을 관장하는 뇌간 구조물들 간 연결망의 변화로 인해 발생하는 것으로 알려져 있다. ${ }^{36} \mathrm{Braak}$
등이 발표한 병리학적 단계에 의하면 알파시누클레인 단백 질의 축적으로 형성된 레비체가 뇌간의 제일 아래인 연수에 서부터 대뇌피질까지 올라가는 양상으로 진행된다고 알려져 있어 파킨슨병, 다계통위축증 등 시누클레인병증의 환자에 게서 $\mathrm{RBD}$ 가 전구증상으로 관찰되는 경우가 흔하다. ${ }^{37}$ 알츠 하이머병의 경우에도 레비체를 동반하는 경우가 많지만, 레 비체병(Lewy body disease)과는 달리 대뇌피질과 변연계에 주로 침착되기 때문에 RBD가 동반되는 경우는 흔치 않은 것으로 알려져 있다.

이전 논문들에 의하면 알츠하이머병에서 $\mathrm{RBD}$ 의 발생률 은 $3 \%$ 에서 $11 \%$ 로 보고되고 있다. ${ }^{12}$ 최근의 단면조사 연구에 서도 105 명의 $\mathrm{AD}$ 환자 중 $\mathrm{MSQ}$ 설문에서 $\mathrm{RBD}$ 가 의심되는 환자 15 명 중 실제 수면다원검사상 $\mathrm{RBD}$ 로 확진한 경우는 5 명(4.8\%)이었고, $\mathrm{RBD}$ 는 질환의 기간과 연관이 있어 알츠하 이머병 치매 후기에 관찰된다는 보고가 있다. ${ }^{38}$ 장기간의 코 호트 연구에서도 비슷한 빈도를 보고하고 있다. Postuma 등 이 12 년에 거쳐 93 명의 원발성 $\mathrm{RBD}$ 환자를 추적관찰한 결 과 26명에서 퇴행성 질환이 발생했고, 그중에서 $\mathrm{AD}$ 로 진단 한 경우는 $4 \%$ 였다고 하였다..$^{9}$ 그리고 또 다른 연구에서 91 명 의 원발성 $\mathrm{RBD}$ 를 추적관찰한 결과 8 명(8.8\%)에서 $\mathrm{AD}$ 가 발 생했다고 보고하였다. ${ }^{40}$ 하지만 대부분의 연구에서 $\mathrm{AD}$ 의 진 단기준으로 NINCDS-ADRDA, Diagnostic and Statistical Manual of Mental Disorders, 4th edition 등의 임상 진단기 준을 사용하는 경우가 대부분이었고, 진단기준을 밝히지 않 은 경우도 있었다.

본 연구에서는 $\mathrm{AD}$ 환자의 $24.6 \%$ 에서 $\mathrm{RBD}$ 가 관찰되었다. 이는 기존의 연구결과보다 높은 빈도이다. 하지만 RBDSQ$\mathrm{K}$ 를 이용한 최근 연구에서 23명의 $\mathrm{AD}$ 환자들 중 9 명(39\%) 에서 $\mathrm{RBD}$ 가 관찰된다는 보고가 있었다. ${ }^{41}$ 이는 본 연구에서 보이는 결과와 유사한 결과이다. 이 연구도 $\mathrm{RBD}$ 의 진단에 설문지를 이용하였다는 공통점이 있지만, $\mathrm{AD}$ 의 진단기준으 로 임상적인 진단기준(NINCDS-ADRDA criteria)을 사용하 였다는 점에서 본 연구와 차이가 있다. 물론 원발성 $\mathrm{RBD}$ 를 장기간 추적관찰한 연구들에서 훨씬 낮은 빈도로 $\mathrm{AD}$ 의 발 생을 보고하고 있으므로, 본 연구에서 $\mathrm{AD}$ 환자에서 관찰되 는 $\mathrm{RBD}$ 의 빈도는 과평가되었을 가능성이 있지만, 이전 연구 에서 알츠하이머병 환자들의 병리소견을 확인한 결과 40 $50 \%$ 에서 레비체가 관찰된다는 연구결과를 고려해 보면 알츠 하이머병 환자들에게 $\mathrm{RBD}$ 증상이 관찰되는 원인으로 시누 클레인병증으로 인한 레비체 병리를 공유하는 것이 하나의 원인이라고 생각할 수 있다. ${ }^{13-17}$

이전 연구에서는 레비체를 보인 알츠하이머병 환자가 레 비체를 보이지 않는 환자에 비하여 $\mathrm{APOE} \varepsilon 4$ 의 빈도가 높았 
다는 보고와 더 낮았다는 보고가 함께 있었다. ${ }^{41,42}$ 우리 연구 에서도 $\mathrm{APOE} \varepsilon 4$ 의 유무에 따라 RBD 동반 여부를 확인하였 으나 통계학적으로 유의미한 차이는 없었다. 이는 이전 연구 에서 레비체 동반 여부에 따른 알츠하이머병 환자에서 $\mathrm{APOE}$ $\varepsilon 4$ 발견 빈도가 차이가 없다는 결과와 일치한다. ${ }^{43,44}$

인지기능을 살펴보면 $\mathrm{RBD}$ 를 동반한 환자와 동반하지 않 은 환자를 비교하였을 때 $\mathrm{SNSB}$ 를 통한 자세한 신경심리검 사에서 COWAT-supermarket을 제외한 모든 항목에서 양쪽 환자들 사이에 유의미한 차이는 보이지 않았다. 주의집중력, 기억력, 언어능력, 전두엽 집행기능을 포함한 모든 항목에서 유의미한 차이가 없었기 때문에 한 가지 항목의 차이만을 가 지고 $\mathrm{RBD}$ 에 따라 인지기능의 차이가 있다고 보기는 어려울 것으로 사료된다. 하지만 실행력(executive function)이 RBD 환자에서 향후 퇴행성 질환을 예측할 수 있는 인지라는 이전 의 연구결과를 고려한다면 충분한 환자 수를 확보한 후속연 구가 필요할 것이다. ${ }^{12}$

본 연구는 NIA-AA 기준으로 진단한 알츠하이머병 환자 들 중 양전자단층촬영을 통하여 아밀로이드 병리소견을 확 인한 환자들만 대상으로 $\mathrm{RBD}$ 의 발생률을 확인하였다는 점 에서 의의가 있다. 하지만 $\mathrm{RBD}$ 를 수면다원검사가 아닌 설문 으로 진단했다는 제한점이 있다. 그리고 $\mathrm{RBD}$ 를 보인 환자들 의 파킨슨 증상의 동반 여부를 확인하지 못한 제한점이 있다. 향후 이 환자들에 대하여 단일화된 파킨슨병 계측 척도(unified Parkinson's disease rating scle)를 시행하여 파킨슨병 증상 여부를 확인한다면 더 의미 있는 결과를 얻을 수 있을 것으로 기대한다. 그리고 충분한 표본수를 확보하지 못하여 통계학적 검증력이 높지 않았다는 점 또한 본 연구의 제한점 이다. 그러므로 향후 수면다원검사를 통해 확진한 충분한 환 자군을 대상으로 한 연구가 필요할 것으로 사료된다.

결론적으로 알츠하이머병 환자에서 $\mathrm{RBD}$ 가 드물지 않게 관찰될 수 있는 것으로 보이며, $\mathrm{RBD}$ 를 동반한 치매를 진단 함에 있어서, 레비체 치매뿐 아니라 알츠하이머병을 감별진 단으로 고려할 필요가 있다.

\section{Acknowledgments}

None.

\section{Conflicts of Interest}

The authors have no potential conflicts of interest to disclose.

\section{ORCID iDs}

Hyun-Suk Kim Hyun Joon Lee Dong-Jin Shin Yeong-Bae Lee Young Noh Kee Hyung Park https://orcid.org/0000-0002-6318-5490 https://orcid.org/0000-0001-6295-182X https://orcid.org/0000-0003-4346-4000 https://orcid.org/0000-0001-5952-1423 https://orcid.org/0000-0002-9633-3314 https://orcid.org/0000-0001-6847-6679

\section{Author Contributions}

Conceptualization: Hyun-Suk Kim, Hyun Joon Lee, Dong-Jin Shin, Yeong-Bae Lee, Young Noh, Kee Hyung Park. Data curation: Hyun-Suk Kim, Kee Hyung Park. Formal analysis: Hyun-Suk Kim, Hyun Joon Lee, Kee Hyung Park. Investigation: Hyun-Suk Kim, Kee Hyung Park. Methodology: Kee Hyung Park. Supervision: Kee Hyung Park. Writing_original draf: Hyun-Suk Kim, Hyun Joon Lee, Kee Hyung Park. Writing_review \& editing: Hyun Jun Lee, Kee Hyung Park.

\section{REFERENCES}

1. Schenck CH, Bundlie SR, Ettinger MG, Mahowald MW. Chronic behavioral disorders of human REM sleep: a new category of parasomnia. Sleep 1986;9:293-308.

2. Kang SH, Yoon IY, Lee SD, Han JW, Kim TH, Kim KW. REM sleep behavior disorder in the Korean elderly population: prevalence and clinical characteristics. Sleep 2013;36:1147-1152.

3. Haba-Rubio J, Frauscher B, Marques-Vidal P, et al. Prevalence and determinants of rapid eye movement sleep behavior disorder in the general population. Sleep 2018;41. pii: zsx197.

4. Boeve BF. REM sleep behavior disorder: updated review of the core features, the REM sleep behavior disorder-neurodegenerative disease association, evolving concepts, controversies, and future directions. Ann N Y Acad Sci 2010;1184:15-54.

5. Plazzi G, Corsini R, Provini F, et al. REM sleep behavior disorders in multiple system atrophy. Neurology 1997;48:1094-1097.

6. Gagnon JF, Bédard MA, Fantini ML, et al. REM sleep behavior disorder and REM sleep without atonia in Parkinson's disease. Neurology 2002;59:585-589.

7. Boeve BF, Silber MH, Ferman TJ. REM sleep behavior disorder in Parkinson's disease and dementia with Lewy bodies. J Geriatr Psychiatry Neurol 2004;17:146-157.

8. Plomhause L, Dujardin K, Duhamel A, et al. Rapid eye movement sleep behavior disorder in treatment-naïve Parkinson disease patients. Sleep Med 2013;14:1035-1037.

9. Poryazova R, Oberholzer M, Baumann CR, Bassetti CL. REM sleep behavior disorder in Parkinson's disease: a questionnaire-based survey. J Clin Sleep Med 2013;9:55-59A.

10. Boeve BF, Silber MH, Parisi JE, et al. Synucleinopathy pathology and REM sleep behavior disorder plus dementia or parkinsonism. Neurology 2003;61:40-45.

11. Ferman TJ, Boeve BF, Smith GE, et al. Inclusion of RBD improves the diagnostic classification of dementia with Lewy bodies. Neurology 2011;77:875-882.

12. Galbiati A, Carli G, Hensley M, Ferini-Strambi L. REM sleep behavior disorder and Alzheimer's disease: definitely no relationship? J Alzheimers Dis 2018;63:1-11.

13. Popescu A, Lippa CF, Lee VM, Trojanowski JQ. Lewy bodies in the amygdala: increase of alpha-synuclein aggregates in neurodegenerative diseases with tau-based inclusions. Arch Neurol 2004;61:1915-1919.

14. Hamilton RL. Lewy bodies in Alzheimer's disease: a neuropathological review of 145 cases using alpha-synuclein immunohistochemistry. Brain Pathol 2000;10:378-384.

15. Lippa CF, Schmidt ML, Lee VM, Trojanowski JQ. Antibodies to alphasynuclein detect Lewy bodies in many Down's syndrome brains with Alzheimer's disease. Ann Neurol 1999;45:353-357.

16. Arai Y, Yamazaki M, Mori O, Muramatsu H, Asano G, Katayama Y. Alpha-synuclein-positive structures in cases with sporadic Alzheimer's disease: morphology and its relationship to tau aggregation. Brain Res 2001;888:287-296.

17. Korff A, Liu C, Ginghina C, Shi M, Zhang J; Alzheimer's Disease Neuroimaging Initiative. a-synuclein in cerebrospinal fluid of Alzheimer's disease and mild cognitive impairment. J Alzheimers Dis 2013;36:679688 . 
18. Albert MS, DeKosky ST, Dickson D, et al. The diagnosis of mild cognitive impairment due to Alzheimer's disease: recommendations from the National Institute on Aging-Alzheimer's Association workgroups on diagnostic guidelines for Alzheimer's disease. Alzheimers Dement 2011;7:270-279.

19. McKhann GM, Knopman DS, Chertkow H, et al. The diagnosis of dementia due to Alzheimer's disease: recommendations from the National Institute on Aging-Alzheimer's Association workgroups on diagnostic guidelines for Alzheimer's disease. Alzheimers Dement 2011; 7:263-269.

20. You S, Moon HJ, Do SY, et al. The REM sleep behavior disorder screening questionnaire: validation study of the Korean version (RBDQ-KR). J Clin Sleep Med 2017;13:1429-1433.

21. Park JH, Kwon YC. Modification of the mini-mental state examination for use in the elderly in a non-western society. Part 1. Development of Korean version of mini-mental state examination. Int J Geriatr Psychiatry 1990;5:381-387.

22. Reisberg B, Ferris SH, de Leon MJ, Crook T. The global deterioration scale for assessment of primary degenerative dementia. Am J Psychiatry 1982;139:1136-1139.

23. Hughes CP, Berg L, Danziger WL, Coben LA, Martin RL. A new clinical scale for the staging of dementia. Br J Psychiatry 1982;140:566-572.

24. Lee SA, Paek JH, Han SH, Ryu HU. The utility of a Korean version of the REM sleep behavior disorder screening questionnaire in patients with obstructive sleep apnea. J Neurol Sci 2015;358:328-332.

25. Kim SY, Won CW, Rho YG. The validity and reliability of Korean version of Bathel ADL Index. J Korean Acad Fam Med 2004;25:534-541.

26. Kang Y, Na DL. Seoul neuropsychological screening battery (SNSB). Seoul: Human Brain Research \& Consulting Co, 2003.

27. Li SX, Wing YK, Lam SP, et al. Validation of a new REM sleep behavior disorder questionnaire (RBDQ-HK). Sleep Med 2010;11:43-48.

28. Kang SJ, Choi SH, Lee BH, Kwon JC, Na DL, Han SH. The reliability and validity of the Korean Instrumental Activities of Daily Living (KIADL). J Korean Neurol Assoc 2002;20:8-14.

29. Knopman DS, DeKosky ST, Cummings JL, et al. Practice parameter: diagnosis of dementia (an evidence-based review). Report of the quality standards subcommittee of the American Academy of Neurology. Neurology 2001;56:1143-1153.

30. Jack CR Jr, Bennett DA, Blennow K, et al. NIA-AA research framework: toward a biological definition of Alzheimer's disease. Alzheimers Dement 2018;14:535-562.

31. Curtis C, Gamez JE, Singh U, et al. Phase 3 trial of flutemetamol labeled with radioactive fluorine 18 imaging and neuritic plaque density. JAMA Neurol 2015;72:287-294.
32. Sabri O, Sabbagh MN, Seibyl J, et al.; Florbetaben Phase 3 Study Group. Florbetaben PET imaging to detect amyloid beta plaques in Alzheimer's disease: phase 3 study. Alzheimers Dement 2015;11:964974.

33. Clark CM, Pontecorvo MJ, Beach TG, et al.; AV-45-A16 Study Group. Cerebral PET with florbetapir compared with neuropathology at autopsy for detection of neuritic amyloid- $\beta$ plaques: a prospective cohort study. Lancet Neurol 2012;11:669-678.

34. Stiasny-Kolster K, Mayer G, Schäfer S, Möller JC, Heinzel-Gutenbrunner M, Oertel WH. The REM sleep behavior disorder screening questionnaire-A new diagnostic instrument. Mov Disord 2007;22:23862393.

35. Boeve BF, Molano JR, Ferman TJ, et al. Validation of the Mayo sleep questionnaire to screen for REM sleep behavior disorder in an aging and dementia cohort. Sleep Med 2011;12:445-453.

36. Boeve BF, Silber MH, Saper CB, et al. Pathophysiology of REM sleep behaviour disorder and relevance to neurodegenerative disease. Brain 2007;130:2770-2788

37. Braak H, Del Tredici K, Rüb U, de Vos RAI, Jansen Steur ENH, Braak E. Staging of brain pathology related to sporadic Parkinson's disease. Neurobiol Aging 2003;24:197-211.

38. Wang P, Wing YK, Xing J, et al. Rapid eye movement sleep behavior disorder in patients with probable Alzheimer's disease. Aging Clin Exp Res 2016;28:951-957.

39. Postuma RB, Gagnon JF, Vendette M, Fantini ML, Massicotte-Marquez J, Montplaisir J. Quantifying the risk of neurodegenerative disease in idiopathic REM sleep behavior disorder. Neurology 2009;72: 1296-1300.

40. Wing YK, Li SX, Mok V, et al. Prospective outcome of rapid eye movement sleep behaviour disorder: psychiatric disorders as a potential early marker of Parkinson's disease. J Neurol Neurosurg Psychiatry 2012;83:470-472.

41. Kim HJ, Im HK, Kim J, et al. Brain atrophy of secondary REM-sleep behavior disorder in neurodegenerative disease. J Alzheimers Dis 2016; 52:1101-1109.

42. Samuel W, Alford M, Hofstetter CR, Hansen L. Dementia with Lewy bodies versus pure Alzheimer disease: differences in cognition, neuropathology, cholinergic dysfunction, and synapse density. J Neuropathol Exp Neurol 1997;56:499-508.

43. Stern Y, Jacobs D, Goldman J, et al. An investigation of clinical correlates of Lewy bodies in autopsy-proven Alzheimer disease. Arch Neurol 2001;58:460-465.

44. Tsuang D, Leverenz JB, Lopez OL, et al. APOE $\varepsilon 4$ increases risk for dementia in pure synucleinopathies. JAMA Neurol 2013;70:223-228. 